\title{
Men neme tien deelnemers en één moderator ... Het recept voor het uitvoeren van focusgroep- onderzoek
}

\author{
P.M. Boendermaker, M.E. Schippers, J. Schuling
}

\section{Samenvatting}

In dit artikel wordt de indicatiestelling voor en de uitvoering van focusgroeponderzoek beschreven. Dit is een kwalitatieve onderzoeksmethode die toegepast wordt in explorerend onderzoek. Bij deze onderzoeksopzet initieert men in een groep een gedachtewisseling met behulp van een aantal te voren geformuleerde vragen. De deelnemers moeten ervaring hebben met het te bespreken onderwerp. Met dezelfde vragen wordt in verschillende groepen een dergelijke gedachtewisseling gehouden teneinde de meningen van de deelnemers te achterhalen. Er is geen sprake van een poging tot het bereiken van consensus. Met zorgvuldige rapportage van de resultaten van de analyse van de gesprekken wordt de focusgroepmethode afgerond. De inventarisatie van meningen en ideeën levert over het onderzochte onderwerp een beeld op dat later getoetst kan worden met behulp van andere methoden. (Boendermaker PM, Schippers ME, Schuling J. Men neme tien deelnemers en één moderator... Het recept voor het uitvoeren van focusgroeponderzoek. Tijdschrift voor Medisch Onderwijs 2001;20(4): 147-152.)

\section{Inleiding}

Binnen het wetenschappelijk onderzoek in de geneeskunde neemt kwalitatief onderzoek een bescheiden plaats in. De belangstelling voor dit onderzoek neemt echter toe en aan het belang van de resultaten van dergelijk onderzoek wordt meer waarde gehecht. ${ }^{12}$ Als vorm van kwalitatief onderzoek is in de afgelopen decennia de focusgroepmethode, die al sinds de jaren twintig in gebruik is in de marketingwereld, ook toegepast in de gezondheidszorg en het medisch onderwijs. ${ }^{3-7}$ In dit artikel willen wij de indicatie voor het gebruik van de focusgroepmethode bespreken en de uitvoering van deze vorm van onderzoek uiteenzetten.

Het doel van focusgroeponderzoek is het exploreren van de meningen of motieven van mensen ten aanzien van een onderwerp waar deze mensen bij betrokken zijn of waar ze uit eigen ervaring over kunnen spreken. In de literatuur over focusgroepen ligt de nadruk op de marktverkennende toepassingen. Er wordt gesproken over opdrachtgevers, snelheid van rapporteren, honoreren van deelnemers en gespreksleiders en de totale begroting. ${ }^{3} 8$ Desondanks zijn veel richtlijnen en suggesties uit de literatuur ook van toepassing op het gebruik van deze methode in andere onderzoeksvelden, zoals de gezondheidszorg of het medisch onderwijs.

Recente voorbeelden van het gebruik van focusgroeponderzoek in de gezondheidszorg zijn het onderzoek naar de zorgen van ouders van een acuut ziek klein kind en onderzoek naar patiëntenvoorlichting over orale anti-diabetica in de apotheek. ${ }^{9} 10$ Ook werd recent de focusgroepmethode gebruikt in een onderzoek naar het oordeel van de lezers over Huisarts en Wetenschap en de gebruikers van de website van het NHG en werd bij een onderzoek naar kenmerken van een goede huisarts-opleider ook met succes gebruik gemaakt van deze methode. 1112 


\section{Indicatie/toepassingsgebied}

Powell en Single beschrijven dat de methode bij uitstek geschikt is, wanneer:

1. over een bepaald onderwerp nog niet veel bekend is. De methode is dan explorerend en hypothesegenererend.

2. het te onderzoeken onderwerp complex is en verschillende invalshoeken en onderzoeksmethoden nodig zijn om de validiteit van de uitkomsten na te gaan.

3. een groot aantal variabelen in het onderzoek moet worden teruggebracht tot de meest essentiële. Een focusgroepstudie kan een hulpmiddel zijn voor de onderzoeker om de meest ter zake doende variabelen te selecteren.

4. de gegevens van kwantitatief onderzoek niet eenduidig zijn. Zo kan een kwalitatief onderzoeksvervolg gebruikt worden om de kwantitatieve gegevens goed te kunnen interpreteren.

Uit deze opsomming blijkt dat de focusgroepmethode op zichzelf kan staan, maar ook aan een kwantitatief onderzoek vooraf kan gaan, of tegelijkertijd of zelfs erna uitgevoerd kan worden. Op basis van de gegenereerde gegevens kan bijvoorbeeld een vragenlijst worden gemaakt of aangepast, of kan een ander kwantitatief vervolg worden gekozen. 6

\section{Organisatie}

De eerste vraag bij het organiseren van deze vorm van onderzoek, luidt: hoe stelt men een focusgroep samen? Het insluitcriterium voor deelnemers aan een focusgroeponderzoek is de betrokkenheid of ervaring met het te onderzoeken onderwerp. Homogeniteit kan daarbij belangrijk zijn. Een verschil in betrokkenheid bij het onderwerp tussen de deelnemers aan de focusgroep kan belemmerend werken. Dit geldt bijvoorbeeld voor ouders van verslaafden en verslaafden zelf bij een focusgroeponderzoek over verslavingen.
Als ouders en verslaafden in dezelfde groep zitten, kan dit de discussie bemoeilijken. Sommigen achten het noodzakelijk dat de groepsleden vreemden voor elkaar zijn om ongewenste interactie tussen groepsleden te voorkomen. Morgan en Krueger stellen in hun recent uitgegeven 'Focus group kit' dat ook een statusverschil tussen groepsleden een open gedachtewisseling in de weg kan staan. 313 Het streven naar homogeniteit kan betekenen dat de onderzoeker vooraf op theoretische gronden een verdeling in (homogene) groepen voorstelt (segmentatie). ${ }^{13-15}$

Over het optimale aantal deelnemers aan een focusgroep bestaat in de literatuur een redelijke consensus. Er moeten genoeg deelnemers zijn (een minimum van zes wordt genoemd) om elkaar te stimuleren in het gesprek door het hebben van verschillende meningen en standpunten. Als maximum aantal deelnemers wordt twaalf genoemd. Bij een hoger aantal is er in de discussie geen goede interactie meer mogelijk tussen alle groepsleden.

De duur van een focusgroepgesprek is afhankelijk van het aantal en de soort vragen die aan de groep worden voorgelegd. Langer dan twee uur kan een groep echter niet 'bij de les' zijn.

Het aantal focusgroepgesprekken is afhankelijk van de informatie die gezocht wordt. Te veel gesprekken over hetzelfde onderwerp leiden tot 'redundancy', een theoretisch punt van informatieverzadiging. 13

De vragen die in het focusgroepgesprek worden gesteld, moeten vooraf goed doordacht zijn. De vragen moeten zo geformuleerd zijn dat de gewenste informatie wordt verkregen. Dit vereist dat de onderzoekers, voorafgaand aan het onderzoek, goed nadenken over de vragen, deze bespreken met collega-onderzoekers en ten slotte de vragen testen in een proefopstelling. ${ }^{16}$ 
Veel aandacht verdient ook de keuze van de moderator, de gespreksleider. De rol van de moderator is essentieel voor het goede verloop van het focusgroepgesprek. In de serie 'Focus group kit' is één deeltje zelfs volledig aan de moderator gewijd. ${ }^{17}$ Als eigenschappen en vaardigheden van de moderator worden beschreven: goed geïnformeerd zijn, betrokken zijn bij het onderwerp, interesse hebben voor de opvatting van anderen, in staat zijn om betrokkenheid te creëren, affiniteit hebben met de groep, bekend zijn met explorerende gesprekstechniek (open vragen, doorvragen, concretiseren, samenvatten, et cetera), goed kunnen formuleren en parafraseren, ruimte geven, onverwachte dingen durven zien en daar, zo nodig, aandacht aan geven, en ten slotte goed timemanagement. Het is af te raden dat de onderzoeker zelf als moderator fungeert. De moderator is dan niet onbevooroordeeld en het gevaar bestaat dat de onderzoeker het gesprek in een bepaalde richting stuurt.

\section{Gegevensverzameling}

Voor het registreren van de gesprekken is goede opneemapparatuur nodig. Daarnaast verdient het aanbeveling een extra opname te maken om defecten of storingen aan de apparatuur op te vangen. De opnames worden naderhand zorgvuldig woordelijk uitgetypt (transcriptie). De transcriptie dient als basis voor de analyse. Voor de planning van het onderzoek is het van belang dat de hoeveelheid data niet onderschat wordt. De data die de transcriptie oplevert, bestaan namelijk uit vele pagina's lastig leesbare spreektekst.

\section{Data-analyse}

De analyse van het materiaal is, zoals bij veel kwalitatief onderzoek, het meest tijdrovende deel van het onderzoek. Er zijn globaal gesproken twee methoden: de interpretatieve methode en de geautomatiseerde methode. ${ }^{14}$

\section{De interpretatieve methode}

Deze methode wordt het meest gebruikt. Hierbij nemen de onderzoeker(s) de transcripten door en maken (in de kantlijn) notities over de verschillende onderwerpen die in de tekst aan de orde zijn en die beschouwd worden als belangrijke informatie. Vervolgens wordt het transcript samengevat. Om te voorkomen dat de onderzoekers hierbij selectief te werk gaan, is het verstandig om deze samenvatting te laten controleren door de deelnemers. Dit moet zo snel mogelijk gebeuren, omdat het gesprek dan de deelnemers nog vers in het geheugen ligt. ${ }^{18}$ Als er meer focusgroepen zijn geweest over hetzelfde onderwerp, kan de samenvatting eerst per groep worden becommentarieerd en vervolgens kan een synthese van de samenvattingen nog een keer aan elke groep worden voorgelegd. Als er weinig verschil tussen de groepen is, kan direct de synthese aan de groepen worden voorgelegd.

Tijdens de verdere analyse moeten thema's ontstaan, omdat de grote hoeveelheid informatie uit de gesprekken moet worden gecondenseerd. Dit proces moet zeer kritisch gebeuren omdat het risico bestaat dat het aantal thema's te beperkt of juist veel te uitgebreid wordt. De thema's kunnen eventueel weer samengebracht worden in categorieën. Deze 'clustering' zal uiteindelijk de neerslag moeten vormen van alle gevoerde gesprekken en zal als basis dienen voor de rapportage van het onderzoek (figuur 1).

Het verdient aanbeveling een aantal gesprekken ook door externe onderzoekers te laten analyseren en de verschillende analyses te vergelijken. Hiermee wordt de kans op een vooroordeel van de hoofdonderzoeker(s) verkleind. 
Figuur 1. Voorbeeld van het analyseproces.

\section{Vraagstelling: Wat zijn de kenmerken, eigenschappen van een goede huisarts-opleider?}

Deze vraag werd gesteld aan de deelnemers van de focusgroepen. Tijdens de groepsdiscussie werd het volgende gezegd:

Het moet niet zo zijn dat je de stijl van de opleider moet kopiëren. (haio-5-7-2)

..je moet terug kunnen treden. Niet altijd allemaal zelf willen doen. Dan denk ik dat je eigenlijk de ander de ruimte moet geven om datgene te doen wat je misschien zelf ook wel kan. (hao-7-1)

Maar dat heeft denk ik heel erg veel te maken met die houding. Dat heeft volgens mij te maken met benieuwd zijn naar de potentiële huisarts die in die haio zit. Dus het gaat erom niet dat iemand een kopie van jezelf wordt maar dat je dus als het ware de dokter in de haio wakker maakt. En ja ... wakker maakt, oproept, dat heeft gewoon met je houding te maken en daar is ruimte geven, dat is absoluut inherent maar dat is ook inherent aan het huisarts zijn. (staf-8-2)

Bij het analyseren van de transcripten van de focusgroepgesprekken werden bij de hierboven geciteerde tekst in de kantlijn de volgende korte aantekeningen gemaakt:

"Ruimte geven om zich tot een huisarts met een eigen stijl te ontwikkelen."

"Ruimte geven".

"Ruimte geven, geen kopie/kloon van de opleider worden".

Deze korte kantlijnaantekeningen werden samengevoegd onder het thema 'ruimte geven aan de huisarts-inopleiding', dat weer onderdeel werd van de categorie: 'didactische houding', als één van de antwoorden op de vraag: welke kenmerken heeft een goede huisarts-opleider?

Er ontstaat op deze manier als het ware een (omgekeerde) boomstructuur: de oorspronkelijke vraag (= de stam), de categorieën (de grote takken), die te verdelen zijn in thema's (de kleinere takken), bestaande uit kantlijnaantekeningen of zelfs citaten met gelijke strekking (de blaadjes).

\section{Geautomatiseerde analyse}

Bij geautomatiseerde analyse wordt gebruik gemaakt van computerprogramma's waarmee woorden of combinaties van woorden in een grote hoeveelheid tekstmateriaal gevonden en geregistreerd kunnen worden. Enkele veel gebruikte programma's zijn: The Ethnograph, Kwalitan en ATLAS/ti. Een bezwaar van deze programma's is vooralsnog dat de onderzoeker die meer wil dan woorden tellen, toch zelf eerst de woordgroepen of combi- naties moet definiëren, het codeboek moet maken, en daarmee in feite al een stap op de interpretatieve weg heeft gezet. Computeranalyse van de gesprekken wordt dan ook vooral als extra controle van een interpretatieve analyse aangeraden. ${ }^{18-21}$

\section{Rapportage}

De rapportage moet opgebouwd worden zoals gebruikelijk is bij een onderzoeksartikel, met expliciet aandacht voor de reden 
om de focusgroepmethode te kiezen en de gevolgde werkwijze. Ook het analyseproces moet duidelijk worden beschreven. Het is gebruikelijk bij het beschrijven van de uitkomsten van de analyse om na een gevonden resultaat één of meer letterlijke, ondersteunende citaten uit de gesprekken te vermelden. Deze citaten zijn ook bedoeld als verantwoording van de conclusies die de onderzoekers hebben getrokken. $\mathrm{Zij}$ vormen als het ware een validering van de resultaten. Het komt de overzichtelijkheid ten goede als deze citaten in een afwijkend lettertype afgedrukt worden (figuur 2).

Figuur 2. Voorbeeld van de weergave van citaten in de onderzoeksrapportage.

In een artikel over de consultvoering van huisartsen wordt een conclusie gepresenteerd met twee ondersteunende citaten:

Huisartsen vinden het lastig om een strakke structuur in hun consulten te handhaven.

"een te krappe jas, zo voelt het als je steeds die vaste structuur moet volgen, 't is ook zo onnatuurlijk"

"... elk consult is toch anders, hoe kan ik het dan steeds hetzelfde doen?"

\section{Conclusie}

Focusgroeponderzoek is een kwalitatieve onderzoeksmethode die geschikt is voor onderzoeksvragen die een exploratieve en kwalitatieve benadering vereisen. Er moet een zorgvuldige 'indicatiestelling' zijn binnen een theoretisch kader. Voorwaarde voor het welslagen is verder een nauwkeurige planning en uitvoering. Voorts vraagt het een grote discipline van de onderzoekers om de aanzienlijke hoeveelheid gegevens die het onderzoek oplevert, op een correcte en consistente manier te analyseren. ${ }^{22}$ Als aan deze voorwaarden wordt voldaan, is focusgroeponderzoek een vruchtbare kwalitatieve onderzoeksmethode.

\section{Literatuur}

1. Lagro-Jansen T, Terluin B. Als het verhaal telt. Huisarts Wet 1998;41:271-3.

2. Harding G, Gantley M. Qualitative methods. Beyond the cookbook. Fam Pract 1998;15:76-9.

3. Morgan DL. The focus group guidebook. Focus group kit volume 1. Thousand Oaks: Sage; 1998.

4. Kitzinger J. Introducing focus groups. BMJ 1995;311:299-302.

5. Crabtree BF, Miller WL. Doing qualitative research. Research methods for primary care volume 3 . Newbury Park: Sage; 1992.

6. Powell RA, Single HM. Focus groups. Int J Quality Health Care 1996;8:499-504.

7. Barbour RS. Using focus groups in general practice research. Fam Pract 1995;12:328-34.

8. Stewart DW, Shamdasani PN. Focus groups, theory and practice. Applied social research methods series volume 20. Newbury Park: Sage; 1990.

9. Kai J. What worries parents when their preschool children are acutely ill and why? BMJ 1996;313: 983-6.

10. Timmer JW, Smet PA de, Schuling J, Tromp TF, Jong-van den Berg LT de. Patient education to users of oral hypoglycemic agents: the perspective of Dutch community pharmacists. Pharm World Sci 1999;21:200-4.

11. Zaat JOM, Tasche MJA. H\&W lezen is werk ... maar wel leuk werk. Het oordeel van lezers over Huisarts en Wetenschap, het NHG-katern en de website. Huisarts Wet 2000;43:455-7.

12. Boendermaker PM, Schuling J, Meyboom-de Jong B, Zwierstra RP, Metz JCM. What are the characteristics of the competent general practitioner trainer? Fam Pract 2000;17:547-53.

13. Morgan DL, Planning focus groups. Focus group kit volume 2. Thousand Oaks: Sage; 1998.

14. Morgan DL. Why things (sometimes) go wrong in focus groups. Qualitative Health Research 1995;5:516-23.

15. Knodel J. The design and analysis of focus group studies. In: Morgan DL (redactie). Successful focus groups. Newbury Park: Sage; 1993.

16. Krueger RA. Developing questions for focus groups. Focus group kit volume 3. Thousand Oaks: Sage; 1998.

17. Krueger RA. Moderating focus groups. Focus group kit volume 4. Thousand Oaks: Sage; 1998.

18. Krueger RA. Analyzing and reporting focus group results. Focus group kit volume 6. Thousand Oaks: Sage; 1998. 
19. Miles MB, Huberman AM. Qualitative data analysis. An expanded sourcebook. 2 ed. Thousand Oaks: Sage Publications Ltd.; 1994.

20. Tesch R. Qualitative research. Analysis types and software tools. New York: The Falmer Press; 1990.

21. Reid AO. Computer management strategies for text data. In: Crabtree BF, Miller WL. Doing qualitative research. Newbury Park: Sage Publications; 1992.

22. Mays N, Pope C. Rigour and qualitative research. BMJ 1995;311:109-12.
De auteurs:

P.M. Boendermaker, huisarts, onderwijscoördinator Huisartsopleiding, Rijksuniversiteit Groningen.

M.E. Schippers, arts-assistent, GGZ-Drenthe, Assen. Dr. J. Schuling, huisarts, hoofd Huisartsopleiding, Rijksuniversiteit Groningen.

Correspondentieadres:

P.M.Boendermaker, Afdeling Huisartsopleiding, Disciplinegroep Huisartsgeneeskunde, Rijksuniversiteit Groningen, A. Deusinglaan 4, 9713 AW Groningen, tel: 050-3632982, fax: 050-3637445, p.m.boendermaker@med.rug.nl.

\section{Summary}

The focus of this article is the focus group method, a qualitative research method, which is mainly used in exploratory studies. The indications for the use of this method, its increased use in research in health care and medical education, and instructions for planning and execution are discussed. In a focus group meeting a number of previously formulated topics is discussed. The participants must be familiar with the issues from personal experience. The same topics are discussed in different focus groups and the aim of the discussions is to explore the participants' views on the subjects. Consensus is not sought. The analysis generates a list of opinions and ideas which creates a picture of the subjects of interest that can be used as the basis for further research. The analysis of the information from the (transcript of) focus group sessions requires scrutiny and rigour. When the conditions described in this article are met, within a transparent theoretical framework, the focus group method is a powerful tool for qualitative research. (Boendermaker PM, Schippers ME, Schuling J. Take ten participants and one moderator... The recipe for a focus group study. Dutch Journal of Medical Education 2001;20(4): 147-152.) 